\title{
Efeito dos parâmetros de extrusão termoplástica sobre as propriedades tecnológicas de farinhas pré-cozidas elaboradas com arroz e feijão
}

\author{
Effect of the thermoplastic extrusion parameters on the technological \\ properties of pre-cooked flours prepared with rice and beans
}

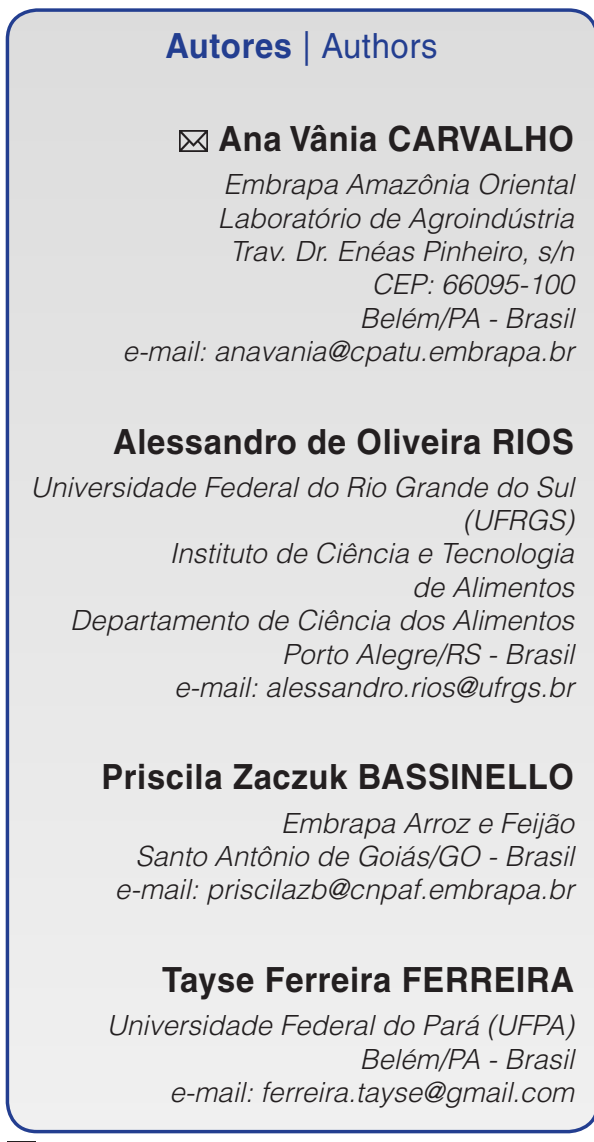

$\triangle$ Autor Correspondente / Corresponding Author

Recebido / Received: 27/06/2011 Aprovado / Approved: 05/09/2012 Publicado / Published: dez./2012

\section{Resumo}

O objetivo deste trabalho foi obter uma farinha pré-gelatinizada elaborada a partir de farinha mista de arroz e feijão, e avaliar a influência das formulações e condições do processamento sobre as propriedades tecnológicas e o teor proteico do produto final. Para a elaboração da farinha pré-gelatinizada mista, utilizou-se o planejamento experimental completo $2^{3}$ com pontos centrais e axiais, testando-se os parâmetros porcentagem de farinha de feijão, umidade e temperatura de processamento, tendo como respostas teor de proteína $\left(Y_{1}\right)$, índice de absorção de água $\left(Y_{2}\right)$ e índice de solubilidade em água $\left(Y_{3}\right)$. As formulações testadas foram processadas em extrusora monorrosca. A temperatura na zona 3 do extrusor variou entre 46 e $114^{\circ} \mathrm{C}$, conforme o planejamento experimental. Os ensaios processados foram submetidos à secagem em estufa com circulação de ar a $50{ }^{\circ} \mathrm{C}$ por cerca de 15 horas, apresentando umidade final entre 4 e $6 \%$, sendo, a seguir, triturados em moinho de facas e armazenados em sacos de polietileno até o momento das análises. Para a variável teor de proteína, somente a porcentagem de farinha de feijão foi significativa e com efeito positivo, ou seja, aumentando-se a quantidade desta farinha, o produto final terá um maior teor proteico, independentemente da temperatura ou da umidade utilizada no processamento. Para a variável índice de absorção de água, a farinha de feijão, o teor de umidade, a temperatura e a interação umidade e temperatura foram significativos. Observou-se maior índice de absorção de água em temperaturas intermediárias $\left(60\right.$ a $\left.80^{\circ} \mathrm{C}\right)$ e altas umidades (17 a 20\%). Para a resposta índice de solubilidade em água, as variáveis umidade, temperatura e a interação umidade e temperatura também foram significativas, observando-se maiores índices de solubilidade em água em temperaturas mais elevadas $\left(100^{\circ} \mathrm{C}\right)$ e umidades mais baixas (14\%). De acordo com o planejamento experimental, a farinha pré-gelatinizada mista de arroz e feijão apresenta as melhores características tecnológicas quando processada sob temperatura de $70{ }^{\circ} \mathrm{C}, 21 \%$ de umidade e com adição de $30 \%$ de farinha de feijão à mistura

Palavras-chave: Extrusão termoplástica; Planejamento experimental; Farinha pré-cozida; Propriedades tecnológicas. 


\section{Summary}

The objective of this study was to obtain a pre-gelatinized flour from a mixed rice and bean flour, and to evaluate the influence of the formulations and processing conditions on the technological properties and protein content of the final product. A complete $2^{3}$ factorial design was adopted with central and axial points to prepare the mixed pre-gelatinized flour, varying the following parameters: percent of bean flour, moisture content and processing temperature. The responses were: protein content $\left(Y_{1}\right)$, water absorption index $\left(Y_{2}\right)$ and water solubility index $\left(Y_{3}\right)$. The formulations were processed in a single screw extruder. The temperature in zone 3 of the extruder varied between 46 and $114{ }^{\circ} \mathrm{C}$, according to the experimental design. The processed products were dried in an air circulating oven at $50{ }^{\circ} \mathrm{C}$ for about 15 hours, presenting a final moisture between 4 and $6 \%$, and were then ground in a knife mill and packed into polyethylene bags until analysed. For the protein content, only the percent bean flour was significant and with a positive effect, that is, the higher the bean flour content, the higher the protein content of the final product, independent of the processing conditions - temperature or moisture. For the water absorption index (WAI), the moisture content, temperature and moisture and temperature interaction were significant. Higher WAI values were observed at intermediate temperatures $\left(60\right.$ to $\left.80^{\circ} \mathrm{C}\right)$ and high moisture contents (17 to $20 \%$ ). For the water solubility index (WSI), the moisture content, temperature and moisture e temperature interaction were again significant, higher WSI values being observed at higher temperatures $\left(100{ }^{\circ} \mathrm{C}\right)$ and lower moisture contents $(14 \%)$. According to the experimental design, the pre-gelatinized mixed rice and bean flour showed the best technological characteristics when processed at a temperature of $70{ }^{\circ} \mathrm{C}$ with $21 \%$ moisture content and the addition of $30 \%$ bean flour to the mix.

Key words: Thermoplastic extrusion; Experimental design; Pre-gelatinized flour; Technological properties. 


\section{Introdução}

Durante o beneficiamento do arroz e do feijão, são gerados grãos partidos e quebrados, classificados como bandinha de feijão e quirera de arroz; esse fato constitui um problema econômico para a indústria, uma vez que tais subprodutos são rejeitados para consumo humano e, portanto, possuem reduzido valor comercial (KADAN et al., 2008; LIMBERGER et al., 2009)

Tendo em vista que esses subprodutos possuem propriedades nutricionais semelhantes aos grãos originais, uma das alternativas para agregação de valor seria transformá-los em ingredientes para alimentos com maior interesse comercial e industrial. Nesse contexto, a tecnologia de extrusão tem desempenhado um papel importante na obtenção de fontes alternativas de carboidratos, transformando matérias-primas amiláceas em produtos de alta aceitabilidade e conveniência (IWE, 1998).

A extrusão termoplástica é um processo no qual a ação mecânica é combinada com o calor para, continuamente, misturar, plasticizar e gelatinizar o amido, desnaturar materiais proteicos e inativar enzimas, formando novas estruturas (DING et al., 2005; CARVALHO et al., 2010; SOUZA e MENEZES, 2008). É uma tecnologia de alta versatilidade e eficiência, baixo custo, alta produtividade, curto tempo de reação e ausência de geração de resíduos (NABESHIMA e GROSSMANN, 2001).

Vários trabalhos têm sido realizados utilizando-se o processo de extrusão para promover a formulação de alimentos mais saudáveis, ricos em fibras e outros componentes, que os caracterizam como alimento funcional, além da possibilidade de diversificação de novos produtos, que atendam às atuais necessidades dos consumidores, principalmente em relação à saúde (SILVA et al., 2008; CARVALHO et al., 2009).

Nesse contexto, a mistura arroz e feijão representa uma ótima combinação nutricional, fornecendo energia e aminoácidos essenciais requeridos em uma dieta saudável, além de fornecer quantidades consideráveis de vitaminas, minerais e fibras (COSTA et al., 2006; WALTER et al., 2008). Considerando-se que a falta de proteínas de boa qualidade e calorias em uma dieta pode resultar em uma má nutrição generalizada, surge então a possibilidade de se aproveitarem o arroz e o feijão mediante o processamento por extrusão termoplástica, com possibilidade de obtenção de produtos com boa qualidade sensorial e nutricional.

A farinha pré-gelatinizada por extrusão tem amplo campo de aplicação na tecnologia de alimentos, podendo ser utilizada como ingrediente no preparo de produtos de panificação, mingaus e sopas instantâneas
(CARVALHO et al., 2009; CLERICE e EL-DASH, 2008; SILVA e ASCHERI, 2009).

A metodologia de superfície de resposta é uma importante ferramenta que correlaciona as propriedades dos produtos e os parâmetros de processo, com o objetivo de desenvolver, otimizar e analisar processos, produtos e formulações (THAKUR e SAXENA, 2000). No processo de extrusão, essa metodologia tem sido utilizada com êxito por diversos autores na otimização e na avaliação dos processos estudados, tendo em vista que as características do produto extrudado variam consideravelmente de acordo com o tipo de extrusor, a configuração da rosca, a umidade do material de alimentação, o perfil de temperatura nas zonas de aquecimento, a velocidade e a taxa de alimentação, entre outros fatores (DING et al., 2005).

Em razão da importância tecnológica que o processo de extrusão termoplástica representa frente aos alimentos de preparo rápido como as farinhas pré-cozidas, instantâneas, pré-gelatinizadas e gelatinizadas, entre outras, o objetivo deste trabalho foi otimizar o processamento de farinha pré-gelatinizada à base de quirera de arroz e bandinha de feijão, avaliando-se o efeito da combinação de umidade da matéria-prima, temperatura de extrusão e quantidade de bandinha de feijão sobre as propriedades tecnológicas e o teor proteico do produto final.

\section{Material e métodos}

\subsection{Obtenção das farinhas de arroz e feijão}

A quirera de arroz e a bandinha de feijão carioca, obtidas da Embrapa Arroz e Feijão, foram moídas em moinho de facas tipo Willye, marca Tecnal, modelo TE-650 (Piracicaba-SP), para a transformação em farinha de arroz e farinha de feijão. A farinha de arroz obtida apresentou $61,58 \%$ das partículas com granulometria entre 2,00 e $0,85 \mathrm{~mm}$ e a farinha de feijão apresentou $84,23 \%$ das partículas entre 2,00 e 0,85 mm. Essas farinhas foram utilizadas no processamento da farinha mista de arroz e feijão pré-gelatinizada por extrusão.

\subsection{Planejamento experimental}

As farinhas pré-gelatinizadas foram processadas testando-se diferentes combinações de farinha de feijão $\left(X_{1}\right)$, temperatura na $3^{a}$ zona de extrusão $\left(X_{2}\right)$ e umidade das matérias-primas $\left(X_{3}\right)$, e otimizadas por meio de delineamento fatorial completo $2^{3}$, com oito pontos lineares, seis pontos centrais e seis axiais (BARROS NETO et al., 1995), tendo como respostas: teor de proteína $\left(Y_{1}\right)$, índice de absorção de água $\left(Y_{2}\right)$ e índice de solubilidade em água $\left(\mathrm{Y}_{3}\right)$. Os níveis das variáveis 
Efeito dos parâmetros de extrusão termoplástica sobre as propriedades tecnológicas de farinhas pré-cozidas elaboradas com arroz e feijão

CARVALHO, A. V. et al.

estudadas no planejamento experimental foram definidos em função de testes preliminares realizados (Tabela 1)

Os ensaios foram processados em extrusora monorrosca (Labor PQ30 - INBRAMAQ, Indústria de Máquinas Ltda., Ribeirão Preto-São Paulo), de configuração e parafuso intercambiáveis, com controle de temperatura nas diferentes zonas de aquecimento e velocidade do parafuso regulável. As temperaturas nas $1^{a}$ e $2^{\mathrm{a}}$ zonas do extrusor foram mantidas constantes (Zona $1=30{ }^{\circ} \mathrm{C}$; Zona $2=40^{\circ} \mathrm{C}$ ); velocidade do parafuso de 170 rpm; taxa de alimentação de $250 \mathrm{~g} \cdot \mathrm{min}^{-1}$, e matriz circular de $3,85 \mathrm{~mm}$. Os ensaios processados foram coletados manualmente e armazenados em sacos de polietileno até o momento das análises.

Todas as respostas do planejamento experimental foram analisadas de acordo com Barros Neto et al.

Tabela 1. Níveis das variáveis estudadas no planejamento experimental.

\begin{tabular}{lcccccc}
\multicolumn{1}{c}{ Variáveis } & \multicolumn{6}{c}{$\begin{array}{c}\text { Níveis codificados e reais das } \\
\text { variáveis }\end{array}$} \\
independentes & $\mathbf{- 1 , 6 8}$ & $\mathbf{- 1}$ & $\mathbf{0}$ & $\mathbf{+ 1}$ & $\mathbf{+ 1 , 6 8}$ \\
\hline Farinha de Feijão $(\%)$ & 13 & 20 & 30 & 40 & 47 \\
Temperatura $\left({ }^{\circ} \mathrm{C}\right)$ & 46 & 60 & 80 & 100 & 114 \\
Umidade $(\%)$ & 12 & 14 & 17 & 20 & 22 \\
\hline
\end{tabular}

(1995), com o auxílio do software Statistica ${ }^{\circledR}$ versão 5.0 (STATSOFT, 1995). O teor de proteínas das farinhas mistas pré-gelatinizadas foi determinado pelo método semimicro Kjeldahl, com fator de conversão de nitrogênio de 6,25, de acordo com método proposto por Horwitz (1997); o índice de absorção de água e o índice de solubilidade em água foram determinados segundo metodologia descrita por Anderson et al. (1969).

\section{Resultados e discussão}

\subsection{Otimização do processo de extrusão de farinhas pré-gelatinizadas de arroz e feijão}

Na Tabela 2, são apresentados os resultados de teor de proteína, índice de absorção de água e índice de solubilidade em água obtidos dos experimentos com farinha pré-gelatinizada de arroz e feijão, de acordo com a matriz do planejamento experimental.

\subsubsection{Teor de proteína}

Os teores de proteína observados para os diferentes ensaios variaram de 10,59\% a 14,76\%. De acordo com os resultados da análise estatística obtidos para a resposta teor de proteína, observou-se efeito significativo somente para a variável farinha de feijão linear, a um intervalo de confiança de 95\%; à medida

Tabela 2. Resultados dos experimentos do planejamento fatorial completo para as variáveis proteína, índice de absorção de água (IAA) e índice de solubilidade em água (ISA), para farinhas pré-gelatinizadas de arroz e feijão.

\begin{tabular}{|c|c|c|c|c|c|c|}
\hline \multirow{2}{*}{ Ensaio } & \multicolumn{6}{|c|}{ Níveis das variáveis em unidades reais } \\
\hline & Farinha de feijão (\%) & Temperatura $\left({ }^{\circ} \mathbf{C}\right)$ & Umidade $^{*}(\%)$ & Proteína* (\%) & $\mathrm{IAA}^{*}\left(g \cdot g^{-1}\right)$ & $\mathrm{ISA}^{*}(\%)$ \\
\hline 1 & 20 & 60 & 14 & 11,53 & 6,45 & 25,73 \\
\hline 2 & 40 & 60 & 14 & 13,73 & 5,37 & 26,70 \\
\hline 3 & 20 & 100 & 14 & 10,59 & 6,65 & 38,21 \\
\hline 4 & 40 & 100 & 14 & 14,00 & 6,58 & 37,57 \\
\hline 5 & 20 & 60 & 20 & 11,98 & 6,98 & 21,51 \\
\hline 6 & 40 & 60 & 20 & 13,47 & 7,27 & 20,21 \\
\hline 7 & 20 & 100 & 20 & 11,27 & 6,64 & 23,57 \\
\hline 8 & 40 & 100 & 20 & 13,18 & 6,46 & 23,35 \\
\hline 9 & 13 & 80 & 17 & 10,43 & 6,81 & 29,90 \\
\hline 10 & 47 & 80 & 17 & 14,76 & 6,60 & 30,41 \\
\hline 11 & 30 & 46 & 17 & 12,88 & 6,73 & 26,14 \\
\hline 12 & 30 & 114 & 17 & 12,83 & 6,59 & 28,78 \\
\hline 13 & 30 & 80 & 12 & 13,42 & 6,25 & 37,59 \\
\hline 14 & 30 & 80 & 22 & 12,40 & 7,47 & 23,42 \\
\hline 15 & 30 & 80 & 17 & 12,72 & 6,86 & 27,50 \\
\hline 16 & 30 & 80 & 17 & 13,02 & 6,82 & 28,90 \\
\hline 17 & 30 & 80 & 17 & 13,15 & 6,74 & 30,24 \\
\hline 18 & 30 & 80 & 17 & 12,30 & 7,16 & 29,80 \\
\hline 19 & 30 & 80 & 17 & 12,99 & 7,01 & 28,44 \\
\hline 20 & 30 & 80 & 17 & 12,63 & 7,19 & 29,02 \\
\hline
\end{tabular}

*Média de três replicatas. 
Efeito dos parâmetros de extrusão termoplástica sobre as propriedades tecnológicas de farinhas pré-cozidas elaboradas com arroz e feijão

CARVALHO, A. V. et al.

que se utiliza maior porcentagem de farinha de feijão no processamento das farinhas pré-gelatinizadas, obtém-se efeito positivo na resposta, ou seja, maior teor de proteínas no produto final (Tabela 3).

Os resultados indicaram que $86 \%$ da variabilidade na resposta do teor de proteínas pode ser explicada pelo modelo $\left(r^{2}=0,86\right)$. Pela análise de variância para a regressão a $5 \%$ de significância, o valor de $F_{\text {calculado }}$ foi 25,63 vezes o de $F_{\text {tabelado. }}$. Dessa forma, além de o modelo ser significativo, é também preditivo dentro da faixa experimental estudada, pois, segundo Barros Neto et al. (1995), para que uma regressão seja não apenas estatisticamente significativa, mas também válida para fins preditivos, o valor de $F_{\text {calculado }}$ deve ser, no mínimo,
4 a 5 vezes o valor de $F_{\text {tabelado }}$ e o $r^{2}$ deve ser maior ou igual a $60 \%$.

O modelo ajustado utilizando-se apenas os fatores significativos, obtido para a proteína em função das variáveis estudadas, está apresentado abaixo (Equação 1):

$y=12,66+1,19 x$

em que: $y=\%$ proteína; $x_{1}=\%$ farinha de feijão.

O teor máximo de proteína (15\%) foi atingido quando se utilizaram $47 \%$ de farinha de feijão na formulação (Figura 1); porém, valores entre 12,30 e 14\% foram alcançados quando se utilizaram entre 30 e $40 \%$ de farinha de feijão. Este comportamento pode ser explicado

Tabela 3. Efeitos estimados pelo modelo de regressão para a variável proteína.

\begin{tabular}{lcccc}
\multicolumn{1}{c}{ Variáveis independentes } & Efeitos estimados & Erro puro & t-valor & p-valor \\
Interceptação & $\mathbf{1 2 , 8 1 5 8}$ & $\mathbf{0 , 1 2 8 3}$ & $\mathbf{9 9 , 9 0 7 9}$ & $\mathbf{0 , 0 0 0 0}$ \\
Farinha de feijão (L) & $\mathbf{2 , 3 8 9 4}$ & $\mathbf{0 , 1 7 0 3}$ & $\mathbf{1 4 , 0 3 0 4}$ & $\mathbf{0 , 0 0 0 0}$ \\
Farinha de feijão (Q) & $-0,2836$ & 0,1660 & $-1,7089$ & 0,1481 \\
Temperatura (L) & $-0,2580$ & 0,1703 & $-1,15147$ & 0,1903 \\
Temperatura (Q) & $-0,0981$ & 0,1660 & $-0,5927$ & 0,05792 \\
Umidade (L) & $-0,2440$ & 0,1703 & $-1,94326$ & 0,2114 \\
Umidade (Q) & $-0,0602$ & 0,1660 & $-0,3628$ & 0,7316 \\
Farinha de feijão - Temperatura & 0,4055 & 0,12224 & 1,8234 & 0,1278 \\
Farinha de feijão - Umidade & $-0,5497$ & 0,2224 & $-2,4713$ & 0,0564 \\
Umidade - Temperatura & $-0,0848$ & 0,2224 & $-0,3811$ & 0,7188 \\
\hline
\end{tabular}

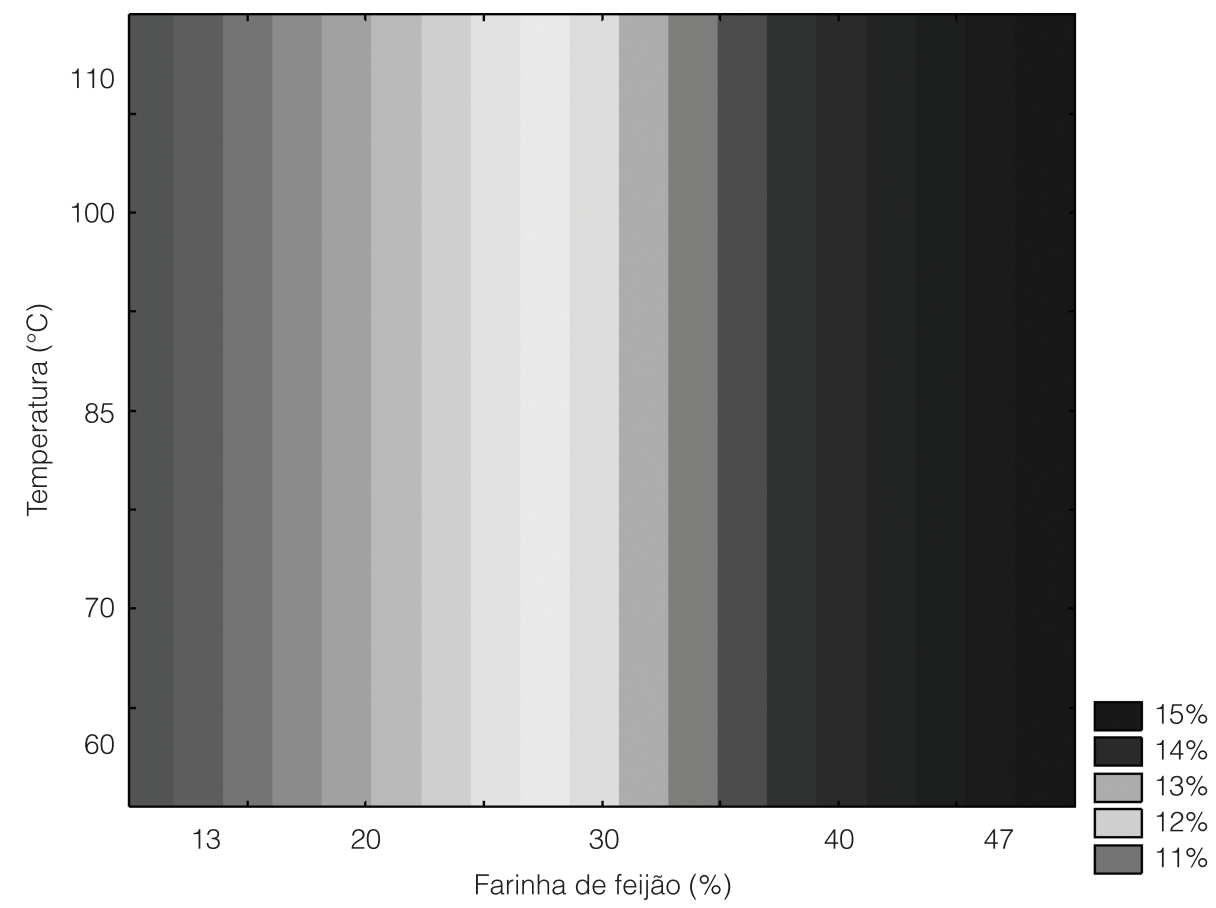

Figura 1. Gráfico de superfície de contorno para a variável proteína (\%) em função da temperatura $\left({ }^{\circ} \mathrm{C}\right)$ e da farinha de feijão (\%), mantendo-se a variável umidade no ponto central. 
Efeito dos parâmetros de extrusão termoplástica sobre as propriedades tecnológicas de farinhas pré-cozidas elaboradas com arroz e feijão

CARVALHO, A. V. et al.

pelo fato de o feijão ser mais rico em proteína do que o arroz. Silva et al. (2007) encontraram teor de proteína para a farinha de quirera de arroz de $7,32 \%$, enquanto Antunes et al. (1995) obtiveram médias de $24,7 \%$ ao estudarem o valor nutricional de farinhas provenientes de quatro cultivares de feijão.

\subsection{2 Índice de absorção de água}

Durante o processo de extrusão, a matéria-prima passa por diversas transformações químicas e estruturais, de modo que o amido é um dos componentes que sofrem as maiores modificações. Os índices de absorção de água (IAA) e de solubilidade em água (ISA) são parâmetros que possibilitam mensurar o grau de transformação sofrido pela fração amilácea dos materiais extrudados (CAMIRE, 2000; GUY, 2001).
O IAA tem relação direta com a quantidade de hidroxilas que se encontram livres para se ligar à água; esse índice variou de 5,37 a 7,47 g. $\mathrm{g}^{-1}$ nos diferentes ensaios de farinha pré-gelatinizada de arroz e feijão. A análise estatística dos dados mostrou que os parâmetros significativos, a 95\% de confiança, foram porcentagem de farinha de feijão quadrática, temperatura quadrática, umidade linear e a interação entre temperatura e umidade lineares (Tabela 4).

As variáveis independentes farinha de feijão quadrática, temperatura quadrática e a interação temperatura e umidade apresentaram efeitos negativos sobre o IAA, indicando que um aumento nessas variáveis contribui para sua diminuição no produto extrudado. Para a variável umidade linear, a elevação deste fator indica um efeito positivo, ou seja, um aumento do IAA.

Tabela 4. Efeitos estimados pelo modelo de regressão para a variável índice de absorção de água.

\begin{tabular}{lcccc}
\multicolumn{1}{c}{ Variáveis independentes } & Efeitos estimados & Erro puro & t-valor & p-valor \\
Interceptação & $\mathbf{6 , 9 6 9 2}$ & $\mathbf{0 , 0 7 6 2}$ & $\mathbf{9 1 , 4 2 6 5}$ & $\mathbf{0 , 0 0 0 0}$ \\
Farinha de feijão (L) & $-0,2066$ & 0,1012 & $-2,0414$ & 0,0967 \\
Farinha de feijão (Q) & $-\mathbf{0 , 2 5 9 4}$ & $\mathbf{0 , 0 9 8 6}$ & $\mathbf{- 2 , 6 2 9 9}$ & $\mathbf{0 , 0 4 6 5}$ \\
Temperatura (L) & 0,0031 & 0,1012 & 0,0307 & 0,9767 \\
Temperatura (Q) & $\mathbf{- 0 , 2 8 8 7}$ & $\mathbf{0 , 0 9 8 6}$ & $\mathbf{- 2 , 9 2 7 0}$ & $\mathbf{0 , 0 3 2 7}$ \\
Umidade (L) & $\mathbf{0 , 6 3 7 9}$ & $\mathbf{0 , 1 0 1 2}$ & $\mathbf{6 , 3 0 3 6}$ & $\mathbf{0 , 0 0 1 5}$ \\
Umidade (Q) & $-0,1477$ & 0,0986 & $-1,4973$ & 0,1946 \\
Farinha de feijão - Temperatura & 0,1330 & 0,1322 & 1,0063 & 0,03605 \\
Farinha de feijão - Umidade & 0,3139 & 0,1322 & 2,3746 & 0,0636 \\
Umidade - Temperatura & $\mathbf{0 , 6 3 8 9}$ & $\mathbf{0 , 0 1 3 2 2}$ & $\mathbf{- 4 , 8 3 3 6}$ & $\mathbf{0 , 0 0 4 7}$ \\
\hline
\end{tabular}

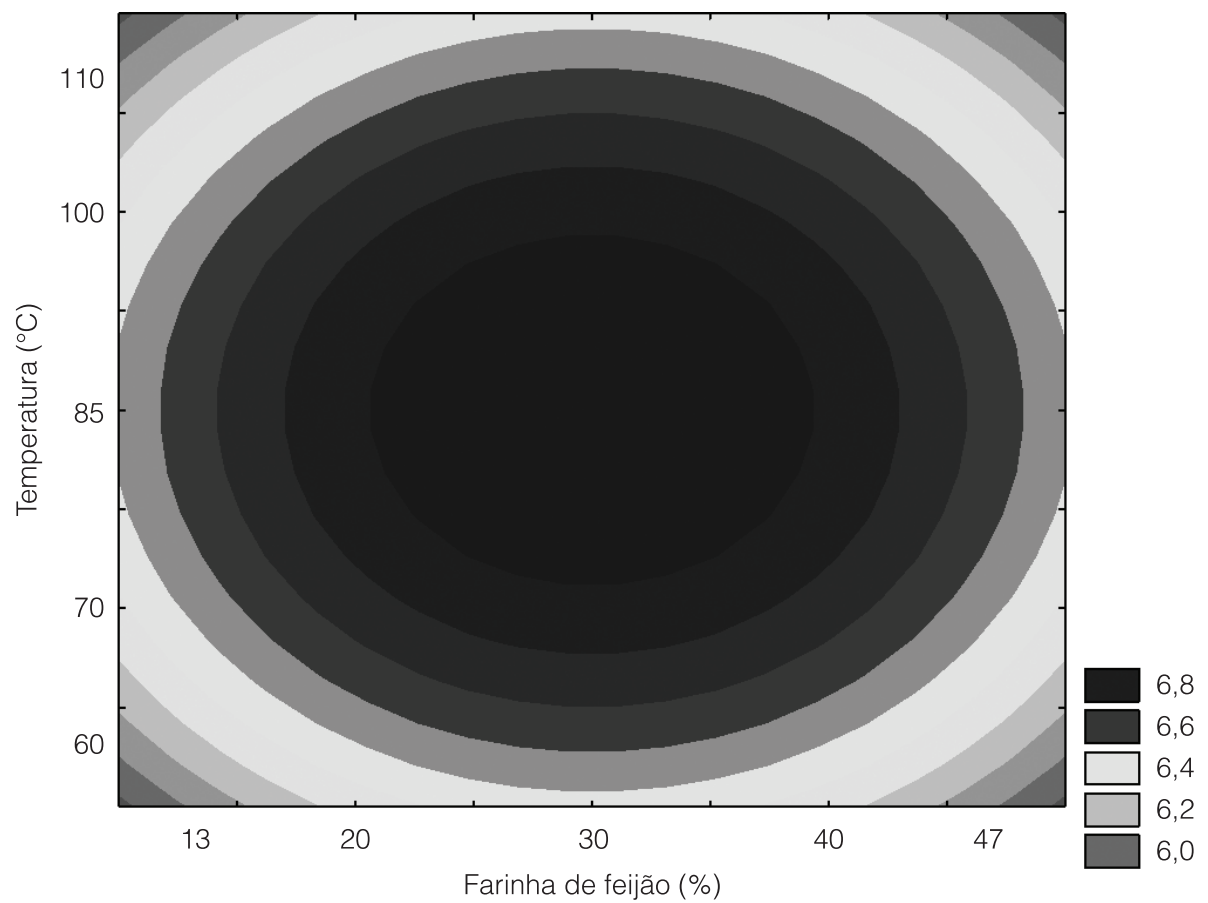

Figura 2. Gráfico de superfície de contorno para a variável índice de absorção de água em função da temperatura ( $\left.{ }^{\circ} \mathrm{C}\right)$ e farinha de feijão (\%), mantendo-se a variável umidade no ponto central. 
Efeito dos parâmetros de extrusão termoplástica sobre as propriedades tecnológicas de farinhas pré-cozidas elaboradas com arroz e feijão

CARVALHO, A. V. et al.

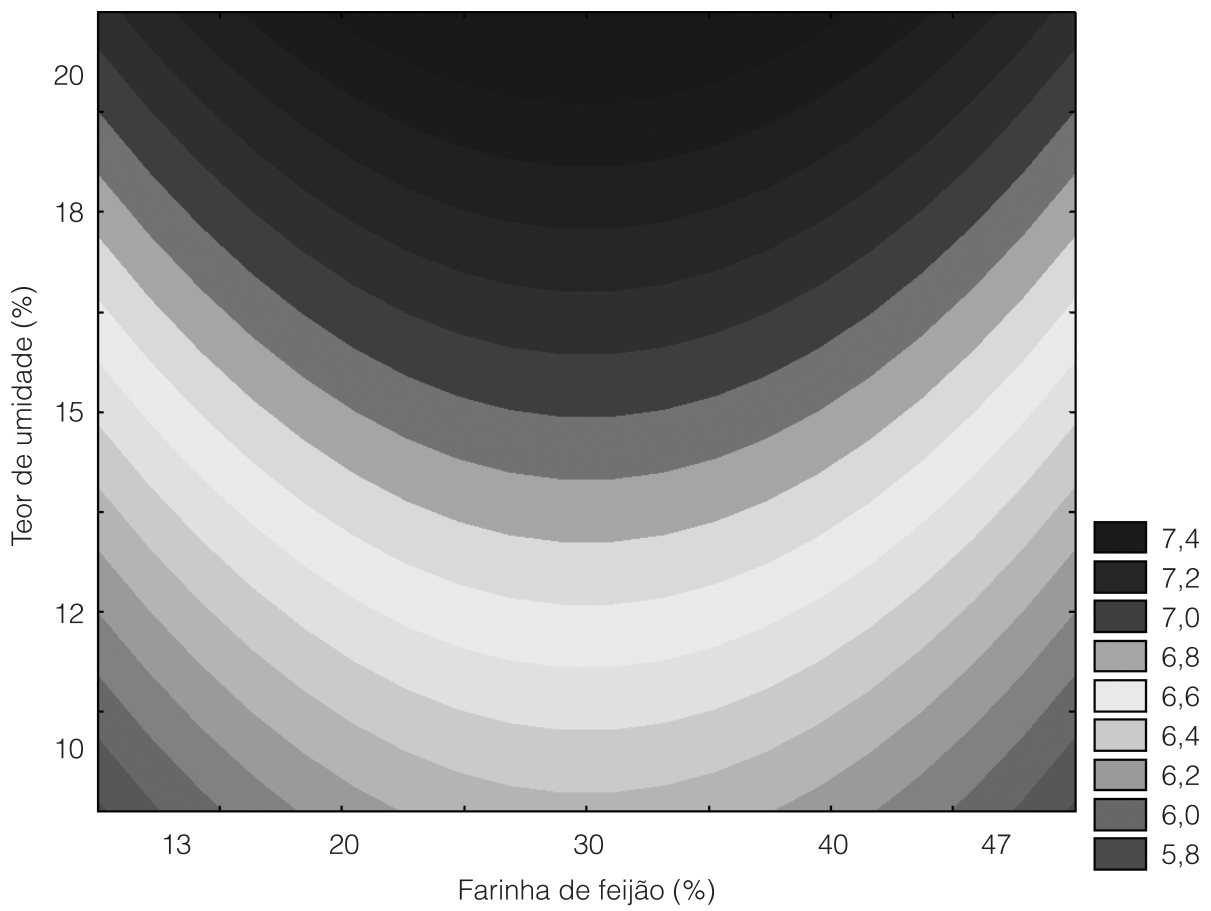

Figura 3. Gráfico de superfície de contorno para a variável índice de absorção de água em função da umidade (\%) e farinha de feijão (\%), mantendo-se a variável temperatura no ponto central.

De acordo com a análise de variância, observou-se valor de $r^{2}$ de 0,72 , indicando que o modelo explica $72 \%$ da variação dos dados observados para o IAA. Observou-se, também, que o valor de $F_{\text {calculado }}$ foi três vezes o valor de $F_{\text {tabelado }}$, a $5 \%$ de significância, tornando o modelo, além de significativo, também preditivo.

O modelo ajustado, utilizando-se apenas as variáveis significativas, obtido para o índice de absorção de água em função das variáveis estudadas está apresentado a seguir (Equação 2):

$y=6,91-0,14 x_{2}^{2}+0,32 x_{3}-0,32 x_{2} \cdot x_{3}$

em que: $y=I A A ; x_{2}=$ temperatura; $x_{3}=$ umidade.

$O$ gráfico da Figura 2 indica que o IAA atingiu valores máximos quando se extrudou a mistura sob condições intermediárias, isto é, 30\% de farinha de feijão a $80{ }^{\circ} \mathrm{C}$. Por sua vez, o aumento da umidade influencia positivamente o IAA, sendo a formulação com $22 \%$ de umidade a que apresentou maior IAA (Figura 3).

Segundo Silva e Ascheri (2009), altos teores de umidade na extrusão promovem lubrificação da rosca do extrusor, diminuindo a degradação do amido e, consequentemente, aumentando o IAA. Clerice e El-Dash (2008) obtiveram pães sem glúten, com textura semelhante à do pão de trigo, usando farinhas pré-gelatinizadas extrudadas a $180^{\circ} \mathrm{C}$ e $20 \%$ de umidade, indicando que altos IAA podem ser importantes na formação de ligações com hidroxilas. Conforme expõe Silva et al. (2008), um bom IAA em amidos pré-gelatinizados, ou seja, valores em geral superiores a $6 \mathrm{~g} \cdot \mathrm{g}^{-1}$, facilita a interação destes com a água e favorece o ganho de peso dos produtos em que são utilizados, aumentando seu rendimento.

\subsection{3 Índice de solubilidade em água}

O índice de solubilidade em água (ISA) é empregado como medida de grau de dextrinização do amido durante a extrusão, isto é, quanto maior a degradação das moléculas de amido em moléculas menores, maior o ISA. Segundo Carvalho et al. (2002), um baixo ISA indica menor degradação do amido por ruptura da molécula e, assim, maior absorção de água, o que refletirá positivamente no IAA.

Para o ISA, obteve-se influência significativa a $95 \%$ de confiança para as variáveis independentes temperatura linear, temperatura quadrática, umidade linear e a interação entre umidade e temperatura. A variável temperatura linear apresentou efeito positivo sobre o ISA, indicando que um aumento desse fator contribui para a elevação no ISA das farinhas pré-gelatinizadas. Por sua vez, a temperatura quadrática, a umidade linear e a interação umidade e temperatura lineares apresentaram efeitos negativos, ou seja, a elevação desses fatores indica uma diminuição no ISA das farinhas extrudadas (Tabela 5).

De acordo com a análise de variância, o valor para o $r^{2}$ foi de 0,89 , o que indica que $89 \%$ da variabilidade na resposta é explicada pelo modelo. A relação $\mathrm{F}_{\text {Calculado }} / \mathrm{F}_{\text {Tabelado }}$ para a regressão apresentou valor de 
Efeito dos parâmetros de extrusão termoplástica sobre as propriedades tecnológicas de farinhas pré-cozidas elaboradas com arroz e feijão

CARVALHO, A. V. et al.

10,42, concluindo-se que o ajuste do modelo é bom, podendo ser utilizado para fins preditivos.

O modelo ajustado, utilizando-se apenas as variáveis significativas, obtido para o índice de solubilidade em água em função das variáveis estudadas está apresentado a seguir (Equação 3):

$y=29,05+2,42 x_{2}-1,02 x_{2}^{2}-4,65 x_{3}-2,27 x_{2} \cdot x_{3}$

em que: $y=I S A ; x_{2}=$ temperatura; $x_{3}=$ umidade.

A partir da superfície de contorno (Figura 4), verifica-se a influência positiva da temperatura no ISA, o qual aumenta com a elevação da temperatura, de modo que índices mínimos de solubilidade foram atingidos quando se processou em condições mais brandas de temperatura $\left(60{ }^{\circ} \mathrm{C}\right)$ e índices máximos sob condições extremas de temperatura $\left(114^{\circ} \mathrm{C}\right)$. Verifica-se ainda que o aumento da umidade da matéria-prima implica em diminuição do ISA, que tendeu a ser mínimo em altas umidades (Figura 5). Clerice e El-Dash (2008) obtiveram comportamento semelhante extrudando farinha de arroz pura, constatando que os menores teores de umidade e as mais altas temperaturas foram as variáveis que mais influenciaram no aumento do valor de ISA.

Em geral, materiais pouco úmidos extrudados a altas temperaturas apresentam um índice de solubilidade maior e, em contrapartida, um índice de absorção de água menor. Vários estudos confirmam tal comportamento, como o estudo de Ding et al. (2005), em que os autores avaliaram o efeito das condições de extrusão nas propriedades físico-químicas de extrudados à base de

Tabela 5. Efeitos estimados pelo modelo de regressão para a variável índice de solubilidade em água.

\begin{tabular}{lcccc}
\multicolumn{1}{c}{ Variáveis independentes } & Efeitos estimados & Erro puro & t-valor & p-valor \\
Interceptação & $\mathbf{2 9 , 0 6 0 7}$ & $\mathbf{0 , 3 9 7 0}$ & $\mathbf{7 3 , 1 9 2 8}$ & $\mathbf{0 , 0 0 0 0}$ \\
Farinha de feijão (L) & $-0,0451$ & 0,5271 & $-0,0857$ & 0,9350 \\
Farinha de feijão (Q) & $-0,1410$ & 0,5137 & $-0,2744$ & 0,7948 \\
Temperatura (L) & $\mathbf{4 , 8 3 5 6}$ & $\mathbf{0 , 5 2 7 1}$ & $\mathbf{9 , 1 7 3 5}$ & $\mathbf{0 , 0 0 0 0}$ \\
Temperatura (Q) & $\mathbf{- 1 2 , 0 4 9 5}$ & $\mathbf{0 , 5 1 3 7}$ & $-\mathbf{3 , 9 8 9 3}$ & $\mathbf{0 , 0 1 0 4}$ \\
Umidade (L) & $\mathbf{- 9 , 2 9 1 9}$ & $\mathbf{0 , 1 5 2 7 1}$ & $-\mathbf{1 7 , 6 2 7 3}$ & $\mathbf{0 , 0 0 0 0}$ \\
Umidade (Q) & 0,1060 & 0,5137 & 0,2062 & 0,8447 \\
Farinha de feijão - Temperatura & $-0,1326$ & 0,6884 & $-0,1926$ & 0,8548 \\
Farinha de feijão - Umidade & $-0,4622$ & 0,6884 & $-0,6713$ & 0,5318 \\
Umidade - Temperatura & $\mathbf{- 4 , 5 3 8 0}$ & $\mathbf{0 , 6 8 8 4}$ & $-\mathbf{6 , 5 9 1 8}$ & $\mathbf{0 , 0 0 1 2}$ \\
\hline
\end{tabular}

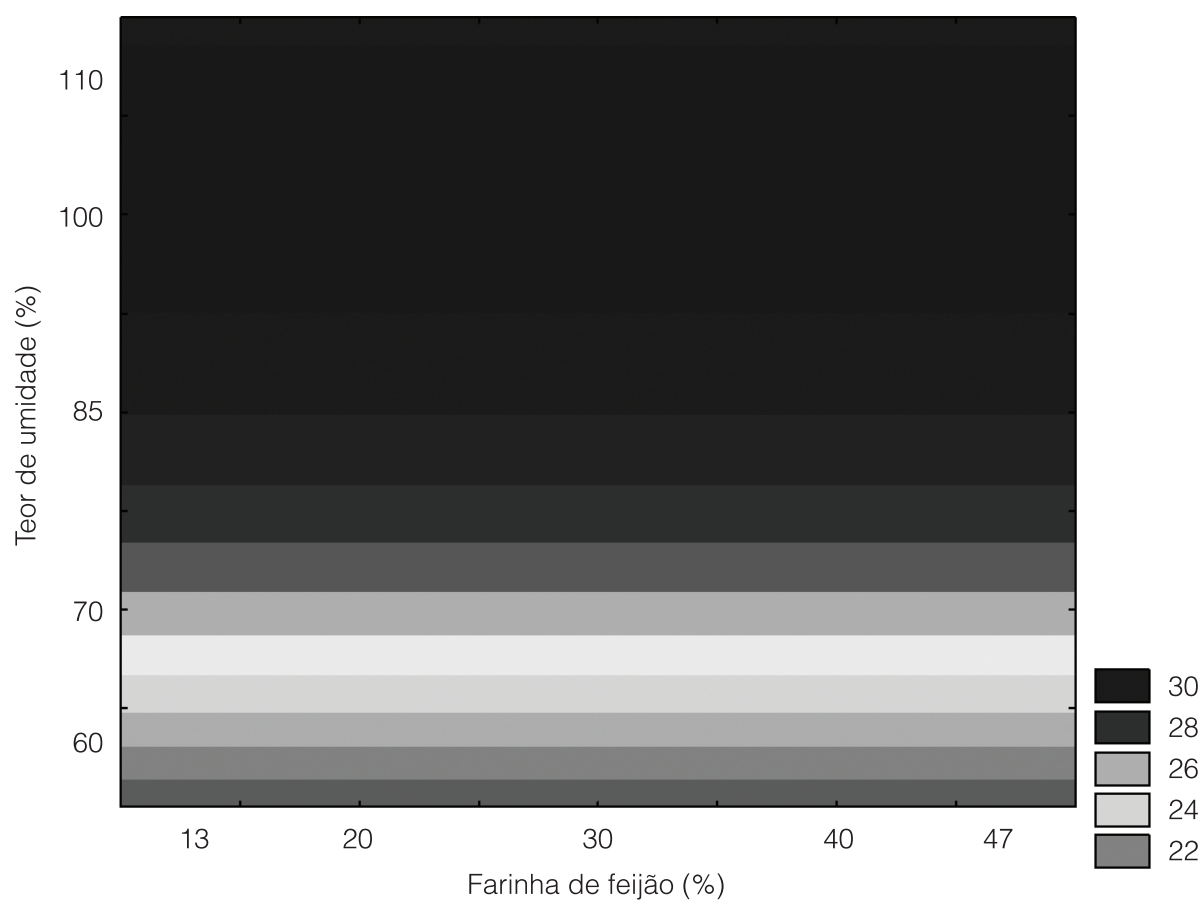

Figura 4. Gráfico de superfície de resposta para a variável índice de solubilidade em água em função da temperatura ( $\left.{ }^{\circ} \mathrm{C}\right)$ e da farinha de feijão (\%), mantendo-se a variável umidade no ponto central. 
Efeito dos parâmetros de extrusão termoplástica sobre as propriedades tecnológicas de farinhas pré-cozidas elaboradas com arroz e feijão

CARVALHO, A. V. et al.

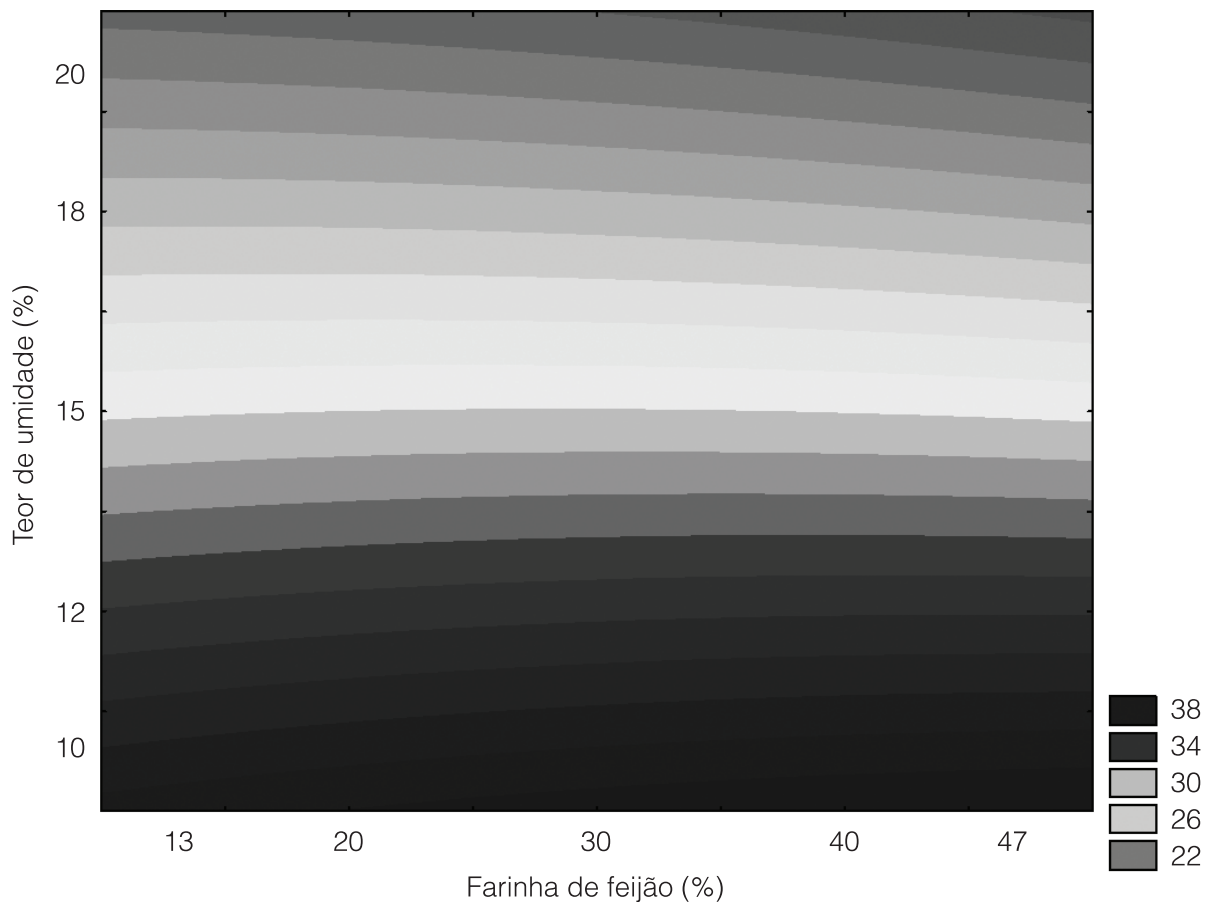

Figura 5. Gráfico de superfície de resposta para a variável índice de solubilidade em água em função da umidade (\%) e da farinha de feijão (\%), mantendo-se a variável temperatura no ponto central.

arroz e verificaram que amostras com alto teor de umidade (22 a 24,73\%) obtiveram maiores valores de IAA $(6,95$ a $\left.7,65 \mathrm{~g} \cdot \mathrm{g}^{-1}\right)$, enquanto o ISA apresentou crescimento quando os materiais foram extrudados com umidades menores (11,27 a 14\%) e altas temperaturas (140 a $\left.153,6^{\circ} \mathrm{C}\right)$.

\section{Conclusão}

Uma vez que as características tecnológicas são primordiais para a obtenção de uma farinha pré-gelatinizada de qualidade e considerando-se que, para produtos de panificação, é interessante que essa farinha apresente alto índice de absorção de água e valores intermediários ou baixos de solubilidade em água, a farinha pré-gelatinizada obtida a partir da extrusão de farinha mista de arroz e feijão apresentou as melhores características tecnológicas e nutricionais quando processada sob temperatura de $70{ }^{\circ} \mathrm{C}, 21 \%$ de umidade e com adição de $30 \%$ de farinha de feijão à mistura.

A farinha pré-gelatinizada obtida apresenta possibilidade de utilização como ingrediente em produtos de panificação, como pães, bolos e cookies. Além disso, representa uma alternativa para consumo conjunto de arroz e feijão, possibilitando a ingestão de todos os aminoácidos essenciais, visto que o arroz e o feijão se complementam em termos de fornecimento destes aminoácidos.

O estudo possibilitou o desenvolvimento de um novo produto, a farinha pré-gelatinizada de arroz e feijão, representando uma alternativa de aproveitamento para a quirera de arroz e a bandinha de feijão, atualmente subutilizadas.

\section{Referências}

ANDERSON, R. A.; CONWAY, H. F.; PFEIFER, V. F.; GRIFFIN, L. Gelatinization of corn grits by roll and extrusuion cooking. Cereal Science Today, Saint Paul, v. 14, n. 1, p. 4-11, 1969

ANTUNES, P. L.; BILHALVA, A. B.; ELIAS, M. C. S.; GERMANO, J. D. Valor nutricional de feijão (Phaseolus vulgaris L.), cultivares Rico 23, Carioca, Piratã-1 e Rosinha-G2. Revista Brasileira de Agrociência, Pelotas, v. 1, n. 1, jan./abr. 1995.

BARROS NETO, B.; SCARMINIO, I. S.; BRUNS, R. E. Planejamento e Otimização de Experimentos. 2. ed. Campinas: Editora da UNICAMP, 1995. 299 p.

CAMIRE, M. E. Chemical and nutritional changes in food during extrusion. In: RIAZ, M. N. Extruders in Food Applications. CRC PRESS, 2000. p. 127-147.

CARVALHO, R. V.; ASCHERI, J. L. R.; CAL-VIDAL, J. Efeito dos parâmetros de extrusão nas propriedades físicas de pellets de misturas de farinhas de trigo, arroz e banana. Ciência e Agrotecnologia, Lavras, v. 26, n. 5, p. 1006-1018, 2002.

CARVALHO, A. V.; VASCONCELOS, M. A. M.; SILVA, P. A.; ASCHERI, J. L. R. Produção de snacks de terceira geração por extrusão de misturas de farinhas de pupunha e mandioca. Brazilian Journal of Food Technology, Campinas, v. 12, n. 4, p. 277-284, 2009. http://dx.doi.org/10.4260/BJFT2009800900022 
Efeito dos parâmetros de extrusão termoplástica sobre as propriedades tecnológicas de farinhas pré-cozidas elaboradas com arroz e feijão

CARVALHO, A. V. et al.

CARVALHO, A. V.; VASCONCELOS, M. A. M.; SILVA, P. A.; ASSIS, G. T.; ASCHERI, J. L. R. Caracterização tecnológica de extrusados de terceira geração à base de farinhas de mandioca e pupunha. Ciência e Agrotecnologia, Lavras, v. 34, n. 4, p. 995-1003, jul./ago. 2010. http://dx.doi.org/10.1590/S141370542010000400028

CLERICE, M. T. P. S.; EL-DASH, A. A. Características tecnológicas de farinhas de arroz pré-gelatinizadas obtidas por extrusão termoplástica. Ciência e Agrotecnologia, Lavras, v. 32, n. 5, p. 1543-1550, set./out. 2008. http://dx.doi.org/10.1590/S141370542008000500028

COSTA, G. E. A.; QUEIROZ-MONICI, K. S.; REIS, S. M. P. M.; OLIVEIRA, A. C. Chemical composition, dietary fibre and resistant starch contents of raw and cooked pea, common bean, chickpea and lentil legumes. Food Chemistry, London, v. 94, n. 3, p. 327-330, 2006. http://dx.doi.org/10.1016/j. foodchem.2004.11.020

DING, Q.; AINSWORTH, P.; TUCKER, G.; MARSON, H. The effect of extrusion conditions on the physicochemical properties and sensory characteristics of rice-based expanded snacks. Journal of Food Engineering, Oxford, v. 66, n. 3, p. 283-289, 2005. http://dx.doi.org/10.1016/j.jfoodeng.2004.03.019

GUY, R. Extrusión de los alimentos. Zaragoza: Acribia, 2001. 208 p.

HORWITZ, W. (Ed.). Official Methods of Analysis of the Association of Official Analytical Chemists. 16th ed. Gaithersburg: AOAC, 1997. 850 p.

IWE, M. O. Effects of extrusion cooking on functional properties of mixtures of full-fat soy and sweet potato. Plant Foods for Human Nutrition, Dordrecht, n. 53, p. 37-46, 1998. http://dx. doi. org/10.1023/A: 1008095703026

KADAN, R. S.; BRYANT, R. J.; MILLER, J. A. Effects of milling on functional properties of rice flour. Journal of Food Science, Chicago, v. 73, n. 4, p. 151-154, 2008. http://dx.doi.org/10.1111/ j.1750-3841.2008.00720.x

LIMBERGER, V. M.; COMARELA, C. G.; PATIAS, L. D.; BRUM, F. B.; SILVA, T. E. L. P. Produção de salgadinho extrusado de quirera de arroz para uso na indústria de alimentos. Ciência Rural, Santa Maria, v. 39, n. 9, p. 2590-2594, 2009. http://dx.doi. org/10.1590/S0103-84782009000900032

NABESHIMA, E. H.; GROSSMANN, M. V. E. Functional properties of pregelatinized and cross-linked cassava starch obtained by extrusion with sodium trimetaphosphate. Carbohydrate Polymers, Barking, v. 45, p. 347-353, 2001. http://dx.doi. org/10.1016/S0144-8617(00)00273-3

SILVA, R. F.; ASCHERI, J. L. R.; PEREIRA, R. G. F. A. Composição centesimal e perfil de aminoácidos de arroz e pó de café. Alimentos e Nutrição, Araraquara, v. 18, n. 3, p. 325-330, jul./set. 2007.

SILVA, E. M. M.; ASCHERI, J. L. R. I; ASCHERI, D. P. R.; CARVALHO, L. M. J. Efeito dos parâmetros de extrusão nas características de viscosidade de pasta e índice de absorção de água de macarrões pré-cozidos elaborados a partir de farinha mista de arroz integral e milho obtidos por extrusão. Boletim do CEPPA, Curitiba, v. 26, n. 2, p. 239-254, jul./dez. 2008.

SILVA, R. F.; ASCHERI, J. L. R. Extrusão de quirera de arroz para uso como ingrediente alimentar. Brazilian Journal of Food Technology, Campinas, v. 12, n. 3, p. 190-199, jul./set. 2009. http://dx.doi.org/10.4260/BJFT2009800900012

SOUZA, M. L.; MENEZES, H. C. Otimização do processo de extrusão termoplástica da mistura castanha do Brasil com farinha de mandioca. Ciência e Tecnologia de Alimentos, Campinas, v. 28, n. 3, p. 659-667, jul./set. 2008. http://dx.doi. org/10.1590/S0101-20612008000300023

STATSOFT. Statistic for Windows. versão 5.0. Tulsa: StatSoft, Inc., 1995.

THAKUR, S.; SAXENA, D. C. Formulation of extruded snack food: optimization of ingredients levels using response surface methodology. Lebensmittel-Wissenschaft und-Technologie, v. 33, n. 5, p. 354-361, 2000. http://dx.doi.org/10.1006/ fstl.2000.0668

WALTER, M.; MARCHEZAN, E.; AVILA, L. A. Arroz: composição e características nutricionais. Ciência Rural, Santa Maria, v. 38, n. 4, p. 1184-1192, jul. 2008. http://dx.doi.org/10.1590/S010384782008000400049 